University of Nebraska - Lincoln

DigitalCommons@University of Nebraska - Lincoln

USDA National Wildlife Research Center - Staff Publications
U.S. Department of Agriculture: Animal and Plant Health Inspection Service

February 2005

\title{
Initial comparison: jaws, cables, and cage-traps to capture coyotes
}

John A. Shivik

Daniel J. Martin

Michael J. Pipas

John Turnan

Thomas J. DeLiberto

USDA/APHIS/WS National Wildlife Research Center, Thomas.J.DeLibertot@aphis.usda.gov

Follow this and additional works at: https://digitalcommons.unl.edu/icwdm_usdanwrc

Part of the Environmental Sciences Commons

Shivik, John A.; Martin, Daniel J.; Pipas, Michael J.; Turnan, John ; and DeLiberto, Thomas J., "Initial comparison: jaws, cables, and cage-traps to capture coyotes" (2005). USDA National Wildlife Research Center - Staff Publications. 519.

https://digitalcommons.unl.edu/icwdm_usdanwrc/519

This Article is brought to you for free and open access by the U.S. Department of Agriculture: Animal and Plant Health Inspection Service at DigitalCommons@University of Nebraska - Lincoln. It has been accepted for inclusion in USDA National Wildlife Research Center - Staff Publications by an authorized administrator of DigitalCommons@University of Nebraska - Lincoln. 


\title{
Initial comparison: jaws, cables, and cage-traps to capture coyotes
}

\author{
John A. Shivik, Daniel J. Martin, Michael J. Pipas, John Turnan, and \\ Thomas J. DeLiberto
}

\begin{abstract}
The need for alternative predator capture techniques is increasing because of concerns about the efficiency, selectivity, and injury of currently available capture methods. There also is a need for comparative data evaluating new or seldom used methods. In an initial evaluation, we first surveyed wildlife managers for information on cage-trapping; using these data, we conducted a field study of 4 coyote (Canis latrans) capture systems for animal damage management. We tested the SoftCatch ${ }^{\circledR}$, Collarum ${ }^{\circledR}$, Wildlife Services-Turman, and Tomahawk ${ }^{\circledR}$, systems for capturing coyotes in Arizona and south Texas during 2001 and 2002. We determined capture efficiency and selectivity and performed whole-body necropsies to identify trap-related injuries. Surveys indicated that coyotes usually were captured in large (>1.6-m-length) cage-traps baited with meat or carcasses. In our field evaluation, we estimated a capture efficiency (percentage of coyote captures per capture opportunity) of $0 \%$ for the Tomahawk cage-trap, $87 \%$ for the Collarum, $88 \%$ for the WS-T throw arm, and 100\% for the SoftCatch. Cage-traps were the least selective, capturing 34 noncoyote animals, and Collarums were the most selective, capturing no noncoyote animals. The WS-T and SoftCatch devices showed intermediate selectivity of $50 \%$ and $69 \%$, respectively. All devices showed low injury scores relative to jawed devices in previous studies; $92 \%, 57 \%$, and $92 \%$ of coyotes captured in the Collarum, WS-T, and SoftCatch showed no indicators of poor welfare, respectively.
\end{abstract}

Key words cage-trap, Canis latrans, coyote, efficiency, injury, selectivity, snare, trap

Foothold traps commonly are used to capture coyotes (Canis latrans) for fur, for biological research, and for depredation and population management. In recent years the perception that these devices may inflict serious injury to trapped animals has led to restrictions on use of jawed foothold traps in some areas of the United States (Cockrell 1999). Capture devices also are of international concern, as indicated by agreements among Canada, the European Community, the Russian Federation, and the United States (United
States of America-European Community 1997) related to commercial fur trade. Such concerns highlight the need to monitor newly developed capture systems relative to accepted animal injury standards.

Continuing interest in capture-system technology (Andelt et al. 1999) has promoted recent testing of traditional (Onderka et al. 1990, Skinner and Todd 1990, Phillips et al. 1992), padded (Linhart and Dasch 1992, Phillips et al. 1996, Phillips and Mullis 1996), and otherwise modified traps (Houben et al.

Address for John A. Shivik: USDA, Wildlife Services, National Wildlife Research Center, and Utah State University, 163 BNR Building, Logan, UT 84322-5295, USA; e-mail: john.shivik@aphis.usda.gov. Address for Daniel J. Martin and Thomas J. DeLiberto: USDA, Wildlife Services, National Wildlife Research Center, 4101 LaPorte Ave., Fort Collins, CO 80521, USA. Address for Michael J. Pipas: USDA, Wildlife Services, 6731 West Coal Road, P.O. Box 59, Casper, WY 82602, USA. Address for John Turman: USDA, Wildlife Services, South District \# 5, 9380 Bond Avenue, Suite A, El Cajon, CA 92021, USA. 
1993, Gruver et al. 1996, Hubert et al. 1997) and snares (Phillips 1996, Shivik et al. 2000). Box-type traps generally are thought of as being undesirable for capturing coyotes (Way et al. 2002), and the method was not explored in common wildlife-damage-management methods texts (Hygnstrom et al. 1994); furthermore, Way et al. (2002: 700) concluded that "future studies should conduct a comparison of injuries sustained to coyotes captured in foothold and box-traps and snare devices" as Mowat et al. (1994) did for lynx (Lynx lynx). Box-traps, cable restraints, and other new and alternative devices have been considered (Garrett 1998, 1999) and sometimes are demanded by animal care and use committees. Therefore, thorough evaluations of capture devices are required. The objective of our research was to evaluate 4 coyote capture systems (cage-trap, powered neck-snare, powered footsnare, and padded-jaw trap) for efficiency, selectivity, and injury.

\section{Methods}

\section{Cage-trap survey}

One objective of our research was to evaluate use of cage-traps for capturing coyotes. However, we had no previous experience using cage-traps for coyotes and could not readily find a thorough description of the proper use of cage-traps for coyotes in an animal damage-management scenario, but we wanted to provide a thorough and unbiased evaluation of cage-traps. Therefore, we searched the literature and the Internet, and interviewed trappers who had captured coyotes in cage-traps to identify setting techniques that would maximize trapping success. We then used the information and opinions gathered from our survey to determine how to set cage-traps such that they would have the highest probability of capturing coyotes.

\section{Field testing}

We tested 4 types of capture devices on coyotes in field situations during 2 studies; the first study, conducted from 11 November to 5 December, 2001, was in Mohave County, Arizona, and the second study, conducted from 10 March to 7 April 2002, was in Webb County,Texas. Cage-traps were: Tomahawk $^{\circledR}$ model 110C $(183 \times 50 \times 66 \mathrm{~cm}$, Tomahawk Live Trap Co., Tomahawk, Wisc.). The Collarum ${ }^{\circledR}$ restraint (Green Mountain Inc., Lander, Wyo.) used a baited pull-tab that triggered a pair of coil-spring-powered throw-arms that propelled a

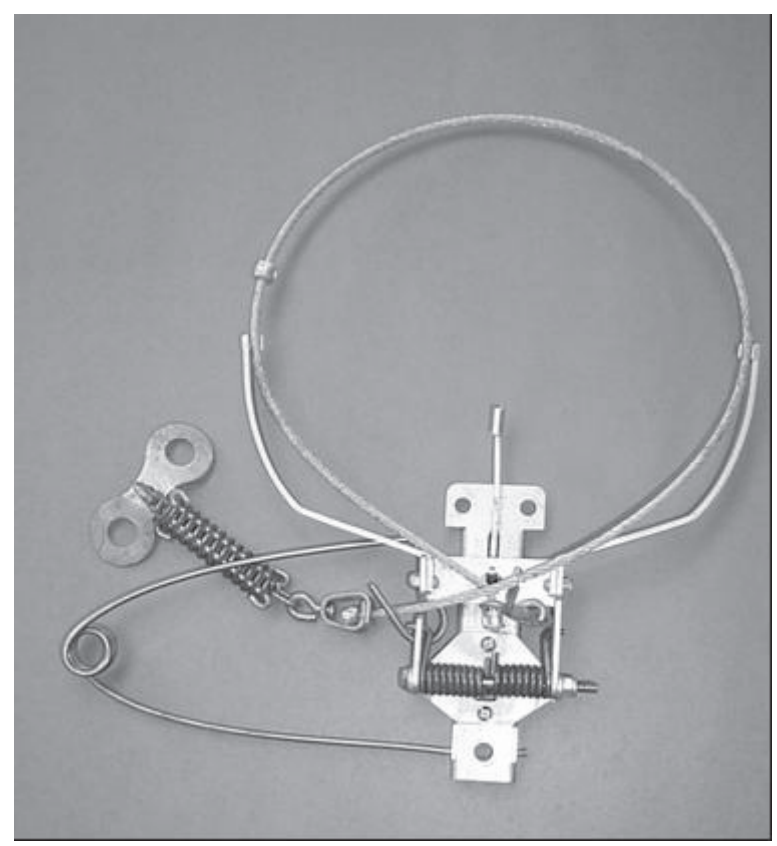

Figure 1. Collarum ${ }^{\circledR}$ Neck Restraint produced by Green Mountain, Inc., Lander, Wyo. (now produced by Wildlife Control Supplies, Simsbury, CT).

0.476-mm (3/16"-diameter) cable loop over the head and onto the neck of a coyote. A stop on the cable prevented coyotes from being choked. The version of the Collarum we tested in this study differed from ones previously evaluated (Shivik et al. 2000) in that it had improved cable clips and an additional horizontal spring that tightened the snare loop as the throw-arm mechanism activated (Figure 1). The Wildlife Services' Turman snare (WS-T, Figure 2) was a throw-arm snare produced by Wildlife Services employees in California (John W. Turman, El Cajon, Calif.). It used a $0.125-\mathrm{mm}$ (1/8"-diameter) cable and cam-lock with a 250-1b break-away sheer pin. The WS-T device was a new

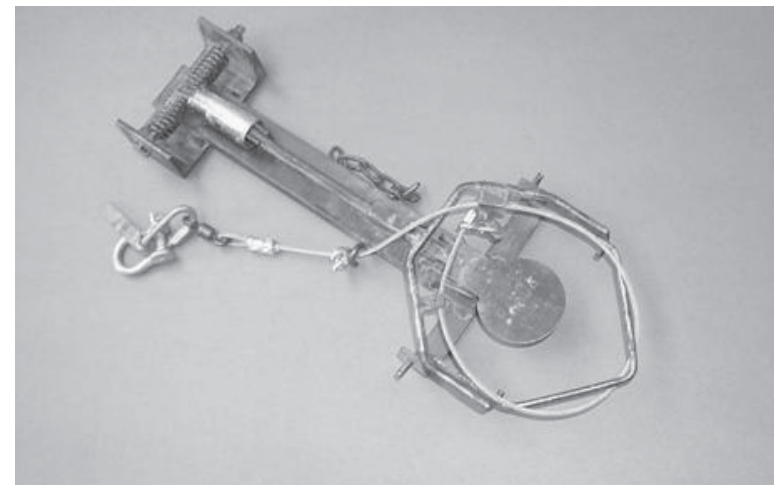

Figure 2. The WS-T powered-snare device. 
design using smaller components and flat and angular iron and not the same device produced by Wildlife Services employees in Idaho and tested previously by Shivik et al. (2000). Lastly, the Soft Catch ${ }^{\circledR}$ trap (Woodstream Corp., Lititz, Penn.) was used as a reference device to provide initial comparisons of efficiency, selectivity, and injury for the devices. In this paper we use the commercial names of products for identification only and not as an endorsement of products by the authors or the United States Department of Agriculture.

We established traplines along unimproved ranch roads and checked traps each morning, which limited the amount of time an animal could be held in a trap to 24 hours. We chose trap sites based on coyote sign and habitat features but randomly selected restraining devices for placement after choosing the trap site. We seated cage-traps into the ground to cover the mesh floor with substrate and baited them with wool and a commercial call lure or lamb (Ovis aries), jackrabbit (Lepus californicus), or deer (Odocoileus bemionus) meat wired to the rear of the trap.

To measure efficiency of each device, we divided number of coyote captures/device by number of potential captures; a potential capture occurred when a coyote triggered the trap and was caught but then escaped or was caught and held (Phillips et al. 1992). Trappers examined tracks and sign at the capture site to identify potential captures. Furthermore, we calculated the capture rate as the number of captures per 1,000 trap-nights. We defined selectivity as number of coyotes captured relative to total number of animals captured and calculated the ratio of noncoyote to coyotes captured.

For analysis of injury, we performed whole-body necropsies (Hubert et al. 1997) in accordance with accepted international standards and procedures (United States of America-European Community 1997, International Organization for Standardization 1999). However, our study was designed as an initial comparison of capture systems for coyote damage management, and we did not attempt to certify traps relative to the standards. For comparison purposes we regarded the following categories as "indicators of poor animal welfare" (United States of America-European Community 1997): fracture, joint luxation proximal to the carpus or tarsus, severance of a tendon or ligament, major periosteal abrasion, severe external hemorrhage or hemorrhage into an internal cavity, major skeletal muscle degeneration, limb ischemia, fracture of a permanent tooth exposing pulp cavity, ocular damage including corneal laceration, spinal cord injury, severe internal organ damage, myocardial degeneration, amputation, or death.The quality of injury was assessed by our veterinarian (TJD), who considered terms such as "major," for example, to mean "deep and more than superficial," and "severe" to be "extensive and detectable grossly." According to the guidelines for humane trapping (United States of America-European Community 1997), a device is considered to exceed the standard if $\geq 80 \%$ of a sample of 20 captured animals show none of these indicators. Because of the ubiquitous use of injury scores in the literature, we also scored injuries according to Onderka et al. (1990), Phillips et al. (1996), and Hubert et al. (1997) to allow some comparison of the devices we tested to values from previous studies.

This study focused on differences among capture devices and not on differences across time, location, or trapper; thus, randomization of device selection occurred at the site level, which was the basic unit of analysis, and we pooled trappers and areas for analysis. We limit our inferences to the use of these devices in Mohave County, Arizona, and Webb County, Texas. Similarly, in analysis of injury, temporal and area effects were not of interest in this study, but injury to animals by capture device were; thus, the captured coyote was the sample unit for injury analysis.

Trappers anesthetized captured coyotes with 2 cc of a 10:1 ketamine:ace promazine solution, then euthanized them with $6 \mathrm{cc}$ intracardial injection of Beuthanasia ${ }^{\circledR}-\mathrm{D}$ solution (Schering-Plough Animal Health Corp., Union, N.J.) and immediately froze the carcasses. We shipped carcasses collected during this study to the United States Department of Agriculture, Wildlife Services National Wildlife Research Center, where a veterinarian (TJD) performed whole-body necropsies.

\section{Results}

\section{Cage-trap survey}

We located 19 publications that mentioned coyote cage-trapping, of which 9 briefly stated that cage-traps could not effectively be used to capture coyotes. We contacted 26 people by phone or email who personally had captured or knew of someone who had captured at least 1 coyote in a cage-trap. Respondents reported capturing 1-545 
Table 1. Information obtained from 2000 and 2001 telephone interviews of trappers that had captured coyotes in cage-traps.

\begin{tabular}{|c|c|c|c|c|}
\hline Target species & $\begin{array}{c}\text { Trap } \\
\text { dimensions }\end{array}$ & $\begin{array}{l}\text { Coyotes } \\
\text { captured }\end{array}$ & Trap nights & $\begin{array}{c}\text { Captures/1,000 } \\
\text { trap nights }\end{array}$ \\
\hline Bobcat ${ }^{\mathrm{a}}$ & $107 \times 38 \times 51$ & 24 & 5,300 & 4.5 \\
\hline Coyote $^{b}$ & $152-183 \times 51 \times 66$ & 29 & 1,447 & 20 \\
\hline San Joaquin kit fox ${ }^{C}$ & $107 \times 38 \times 38$ & 3 & 40,032 & 0.1 \\
\hline Swift fox ${ }^{d}$ & $92 \times 25 \times 31$ & 2 & 1,069 & 1.9 \\
\hline Ocelot ${ }^{\mathrm{e}}$ & $107 \times 41 \times 51$ & 7 & 4,701 & 1.5 \\
\hline
\end{tabular}

a Personal communication, T. Blankenship, Welder Wildlife Foundation, Texas.

b Way (2000).

c Personal communication, B. L. Cypher. California State University, Stanislaus, California.

d Personal communication, J. F. Kamler, Texas Tech University, Lubbock, Texas.

e Laack (1991)

coyotes in cage-traps in urban or suburban environments. In rural areas coyotes were captured as nontargets in traps set for feral hogs (Sus scrofa), ocelots (Leopardus pardalis), bobcats (Lynx rufus), or foxes (Vulpes spp., Table 1).

All of the trappers suggested use of baits and not species-specific coyote lures (such as scat and urine). Baits used included live domestic chicken, domestic chicken parts, live rock dove (Columba livia), rock dove, deer (Odocoileus spp.), rabbit (Sylvilagus spp.), ground-squirrel (Spermophilus spp.), pheasant (Phasianus colchicus), meat scraps, pet food, and canned fish. Also, when respondents set traps in a travel corridor, no bait was used. Of the 17 trappers who had captured coyotes in cagetraps, 3 used small traps $(81-91 \times 25 \times 31 \mathrm{~cm}), 5$ used medium-sized traps $(107-152 \times 30-51 \times$ $30-66 \mathrm{~cm}), 7$ used large traps $(183 \times 51-91 \times 61-79$ $\mathrm{cm})$, and 2 used very large traps (244-305 $\times$ $122-305 \times 91-122 \mathrm{~cm}$ ). Of the coyotes for which data were available for age, 53 adults and 43 juveniles were captured.

Based on findings of our survey, we devised guidelines for setting cage-traps for coyotes. That is, we used traps greater than $1.6 \mathrm{~m}$ in length, covered the trap floor with natural substrate, and baited with carcass parts attached to the inside of the trap. Although conditioning coyotes with pre-baiting also was suggested as a useful method, logistical and practical considerations prevented us from prebaiting traps before initiating the study.

\section{Efficiency}

We set 46 SoftCatch traps, 45 WS-T, 43 Collarum, and 41 cage-traps in Arizona and south Texas during the autumn of 2001 and spring of 2002. During 492 trap-nights we captured no coyotes in cagetraps and had no coyotes activate the trap mechanism (zero efficiency). During 483 trap-nights we captured 13 coyotes (27 per 1,000 trap-nights) coyotes in the Collarum restraint, with 15 potential captures (efficiency $=$ $0.87, \mathrm{SE}=0.09$ ). During 507 trap-nights we captured 7 coyotes $(14 / 1,000$ trap-nights) of the 8 that activated the WS- $\mathrm{T}$ snare (efficiency $=0.88, \mathrm{SE}=$ 0.13 ). We captured all of the 25 coyotes that activated the SoftCatch traps (efficiency $=100 \%$ ) during 517 trap-nights (48 coyotes per 1,000 trap-nights).

\section{Selectivity}

The 34 noncoyote animals captured in cage-traps were 7 bobcats, 12 raccoons (Procyon lotor), 2 armadillos (Dasypus novemcinctus), 2 badgers (Taxidea taxus), 2 javelina (Pecari tajacu, both in the same trap), 1 rattlesnake (Crotalus sp.), 1 roadrunner (Geococcyx californianus), 1 caracara (Polyborus plancus), 1 turkey vulture (Cathartes aura), 2 curve-billed thrashers (Toxostoma curvirostre, both in the same trap), and 3 domestic dogs. However, we captured no coyotes in cage-traps (selectivity $=0$ ). We captured no animals other than coyotes with Collarums (selectivity $=1.0$ ). The WS-T snares captured 7 noncoyote animals (1 bobcat, 2 raccoons, 3 domestic dogs, and 1 feral hog) out of 14 total (selectivity $=0.50, \mathrm{SE}=0.14$ ). In SoftCatch traps, 11 of the 36 animals captured were not coyotes ( 4 bobcats, 1 badger, 3 dogs, 3 raccoons, selectivity $=0.69, \mathrm{SE}=0.08$ ).

\section{Injury}

For each coyote captured, we collected information from a detailed list of injuries, then used these summary data to rank degree of injury according to previously reported interpretive scales (Table 2). Lack of captures precluded injury evaluation for cage traps, but the necropsies of animals captured in other devices provided useful information on injury rates. Most coyotes captured in the Collarum received no or only minor injuries to teeth; howev- 
Table 2. Injury data from whole-body necropsies of coyotes captured with restraining devices during studies in Mohave County Arizona, and Webb County, Texas from November 2001-April 2002.

\begin{tabular}{|c|c|c|c|c|c|c|}
\hline \multirow[b]{2}{*}{ Injury } & \multicolumn{2}{|c|}{$\begin{array}{c}\text { Soft Catch }{ }^{\circledR} \\
n=24 \\
\end{array}$} & \multicolumn{2}{|c|}{$\begin{array}{l}\text { WS-T } \\
n=7 \\
\end{array}$} & \multicolumn{2}{|c|}{$\begin{array}{c}\text { Collarum } \\
n=13\end{array}$} \\
\hline & No. & $\%$ & No. & $\%$ & No. & $\%$ \\
\hline No injury & 1 & 4 & 1 & 14 & 4 & 31 \\
\hline Claw loss & 2 & 8 & 1 & 14 & 0 & 0 \\
\hline Edematous swelling or hemorrhage & 20 & 83 & 4 & 57 & 0 & 0 \\
\hline Cutaneous laceration & 10 & 42 & 2 & 29 & 0 & 0 \\
\hline Laceration on foot pads or tongue & 1 & 4 & 0 & 0 & 0 & 0 \\
\hline Minor (below carpus-tarsus) subcutaneous soft-tissue maceration erosion & 11 & 46 & 1 & 14 & 0 & 0 \\
\hline Major (above carpus-tarsus) subcutaneous soft-tissue maceration erosion & 0 & 0 & 1 & 14 & 0 & 0 \\
\hline Minor (superficial) periosteal abrasion & 1 & 4 & 0 & 0 & 0 & 0 \\
\hline Major (including bone erosion, deep) periosteal abrasion & 0 & 0 & 0 & 0 & 0 & 0 \\
\hline Severance of minor (below carpus-tarsus) tendon or ligament & 0 & 0 & 0 & 0 & 0 & 0 \\
\hline Severance of major (at or above carpus-tarsus) tendon or ligament & 0 & 0 & 1 & 14 & 0 & 0 \\
\hline Amputation of 1 digit & 0 & 0 & 1 & 14 & 0 & 0 \\
\hline Amputation of 2 digits & 0 & 0 & 0 & 0 & 0 & 0 \\
\hline Amputation of 3 or more digits & 0 & 0 & 0 & 0 & 0 & 0 \\
\hline Any amputation above the digits & 0 & 0 & 0 & 0 & 0 & 0 \\
\hline Self-mutilation & 0 & 0 & 0 & 0 & 0 & 0 \\
\hline Severe joint hemorrhage & 1 & 4 & 0 & 0 & 0 & 0 \\
\hline Joint luxation at or below the carpus or tarsus & 1 & 4 & 0 & 0 & 0 & 0 \\
\hline Gross skeletal muscle degeneration (detectable grossly) & 0 & 0 & 0 & 0 & 0 & 0 \\
\hline Simple fracture at or below the carpus or tarsus & 0 & 0 & 0 & 0 & 0 & 0 \\
\hline Any fracture or joint luxation on limb above the carpus or tarsus & 0 & 0 & 1 & 14 & 0 & 0 \\
\hline Compound or comminuted fracture at or below the carpus or tarsus & 0 & 0 & 0 & 0 & 0 & 0 \\
\hline Compression fracture & 0 & 0 & 0 & 0 & 0 & 0 \\
\hline Limb ischemia & 0 & 1 & 14 & 0 & 0 & 0 \\
\hline Severe internal organ damage (internal bleeding) & 0 & 0 & 0 & 0 & 0 & 0 \\
\hline Myocardial degeneration (detectable grossly) & 0 & 0 & 0 & 0 & 0 & 0 \\
\hline Vertebral injury-spinal cord injury & 0 & 0 & 0 & 0 & 0 & 0 \\
\hline Simple rib fracture & 0 & 0 & 0 & 0 & 0 & 0 \\
\hline Comminuted rib fracture & 0 & 0 & 0 & 0 & 0 & 0 \\
\hline Compound rib fracture & 0 & 0 & 0 & 0 & 0 & 0 \\
\hline Permanent tooth fracture exposing pulp cavity-recent (sharp edges, no discoloration) & 2 & 8 & 0 & 0 & 0 & 0 \\
\hline Chipped tooth, not exposing pulp cavity & 2 & 8 & 2 & 29 & 7 & 54 \\
\hline Deciduous tooth fracture exposing pulp cavity & 0 & 0 & 0 & 0 & 0 & 0 \\
\hline Tooth fracture exposing pulp cavity (old, worn edge discoloration) & 1 & 4 & 0 & 0 & 0 & 0 \\
\hline Eye lacerations & 0 & 0 & 0 & 0 & 1 & 8 \\
\hline Ocular injury resulting in blindness & 0 & 0 & 0 & 0 & 0 & 0 \\
\hline Skeletal degeneration & 0 & 0 & 0 & 0 & 0 & 0 \\
\hline Any other fractures (e.g. mandible) & 0 & 0 & 0 & 0 & 0 & 0 \\
\hline Edema, swelling or hemorrhage on head or neck & 0 & 0 & 0 & 0 & 0 & 0 \\
\hline Skin Abrasion, head or neck & 0 & 0 & 0 & 0 & 2 & 15 \\
\hline Death (recorded by field observers only) & 0 & 0 & 1 & 14 & 1 & 8 \\
\hline
\end{tabular}

er, 1 animal was killed because the snare cinched over both the head and neck, causing the snare to choke the coyote before the stop was engaged. Twelve of 13 (rate $=0.92, \mathrm{SE}=0.08$ ) coyotes captured in the Collarum showed no indicators of poor welfare. Most injuries caused by the WS-T device were minor, but there was a broader array of injuries than with the Collarum (Table 2). There was 1 mortality in the WS-T, but we could not determine its cause because the captured coyote showed no injuries except moderate edematous swelling and hemorrhage. Four of the 7 (rate $=0.57$, 
$\mathrm{SE}=0.20)$ coyotes captured showed no indicators of poor welfare in the WS-T device. Most injuries caused by the SoftCatch also were minor (Table 2), and 22 of 24 (rate $=0.92, \mathrm{SE}=0.06$ ) coyotes captured showed no indicators of poor welfare.

Using the system set forth by Onderka et al. (1990), the mean injury scores from the devices we tested were $0.8,41.7$, and 19.8 for the Collarum, WS-T, and SoftCatch devices, respectively. The Hubert et al. (1997) method estimated mean injury scores for the devices we tested as $0.75,42.4$, and 23.3 for the Collarum, WS-T, and SoftCatch devices, respectively. Using the system set forth by Phillips et al. (1996), the mean injury scores from the devices we tested were $2.5,30.7$, and 21.7 for the Collarum, WS-T, and SoftCatch devices, respectively.

\section{Discussion}

\section{Cage-trap survey}

Way et al. (2002) presented the most comprehensive study on the use of cage-traps for coyotes that we could find in the literature; however, anecdotes from other trappers provided a useful basis for our investigation into the use of cage-traps. For example, several trappers suggested that only sick, old, or inexperienced juvenile coyotes could be captured in cage-traps. However, age-structure data from the trappers suggested no such bias because $55 \%$ of captured coyotes were adults, similar to Way et al. (2002), who captured (and recaptured) a majority of healthy adult coyotes. One explanation is that older coyotes in suburban areas are more habituated to crawling though human-constructed obstacles and thus are more vulnerable to cagetraps. In the case of the 1 trapper who reported capturing 545 coyotes in cage-traps, for instance, the traps were set in suburban areas of Los Angeles over the course of the individual's career and targeted habituated coyotes that were not wary of human constructions. We concluded from our survey that, except in suburban nuisance trapping, most captures of coyotes in cage-traps were rare and that it is exceedingly difficult to capture coyotes in cage-traps in agricultural areas in animal damage management circumstances.

\section{Efficiency}

Other authors reported high efficiencies for other trap models, with capture efficiencies of $95 \%$, $95 \%, 89 \%$, and $100 \%$, using the Victor No. 3 NM,
Victor No. 3 Soft Catch, Newhouse No. 4, and the Sterling MJ 600, respectively (Phillips and Mullis 1996). More recently developed devices appeared to be less efficient (78\% for the Belisle, $8.3 \%$ for the Panda, $41 \%$ for the Collarum, and $66 \%$ for the Wildlife Services system; Shivik et al. 2000). However, the devices evaluated in this study (with the exception of the cage-trap) show that new, innovative designs can be more efficient for capturing coyotes.

We were not able to capture coyotes with cagetraps; thus, our estimate of the efficiency of cagetraps was zero. Other trappers using cage-traps for bobcats in Texas reported 4.5 coyotes captured per 1,000 trap-nights (Table 1). Clearly, capture efficiencies are far lower with cage-traps than with other devices. We believe there were 2 primary reasons we were not able to capture coyotes in cagetraps. First, although we incorporated the techniques of past trappers, we were not able to prebait for 2-3 months and condition coyotes to the traps, which was an important component for cagetrapping coyotes as described by Way et al. (2002). Second, our studies were of relatively short duration, and although it is clearly possible to capture coyotes in cage-traps, it takes longer to do so. For now, especially in rural areas, cage-traps are not likely to be feasible tools for capturing coyotes; new cage-trap designs should be explored that incorporate understanding of coyote behavior and wariness.

Capture efficiencies using previous versions of the Collarum were relatively low (41\%, Shivik et al. 2000), but the modified device we tested included a secondary throw-arm, which greatly improved efficiency. The Collarum may be more difficult to set appropriately compared to jawed traps, and animals have the additional behavioral requirement of pulling a tab rather than stepping on a disguised pan, which also may limit the capture rates of the Collarum (27 coyotes/1,000 trap-nights vs. 48 coyotes/1,000 trap-nights for the SoftCatch; $\chi_{1}^{2}=2.71, P$ $=0.10$ ) relative to hidden, behaviorally passive capture devices.

The WS-T device also was efficient, with $88 \%$ of potential captures resulting in actual captures, an efficiency approaching that of a jawed trap, and improved efficiency relative to previous designs (Shivik et al. 2000). However, the capture rate (14 coyotes/1,000 trap-nights) of the WS-T was low relative to the other devices tested, and we believe this was due to our setting technique. We used a 5 
$\mathrm{cm} \times 8 \mathrm{~cm} \times 2 \mathrm{~cm}$ foam block beneath the pan to establish pan tension, which probably excluded some captures by not having the sensitivity and adjustability of other pan-tension systems (Phillips and Gruver 1996). This device requires further testing.

SoftCatch traps performed well in this study, with efficiency similar to that previously reported (Phillips and Mullis 1996). They may outperform the other devices tested due to their relative simplicity, plus the advantage of being a design more common and familiar to most trappers.

\section{Selectivity}

Cage-traps performed poorly in regard to selectivity in this and prior studies (Way et al. 2002). It is clear that modifications to preclude nontarget captures are necessary before cage-traps can be recommended for coyotes under most animal damage management situations. Finding coyote-specific attractants rather than using broadly attractive carrion baits may be essential for improving the selectivity of cage-traps.

As in previous research (Shivik et al. 2000), the Collarum was particularly selective for coyotes (100\%). The baited top and capture mechanism is relatively species-specific, and the mechanics of the device make capture of other species unlikely. The WS-T device was intermediately selective, and we believe that a modified pan-tension design may improve the selectivity of the device. The SoftCatch trap also showed intermediate selectivity for coyotes. Modifications that could increase selectivity also may act to decrease efficiency; therefore, innovative approaches are required to optimize both aspects of capture devices.

\section{Injury}

Sample sizes were low for injury analyses on all but SoftCatch traps, and we encourage other authors to more thoroughly examine the snare-type designs that we examined. Furthermore, because our research was focused on coyotes, we did not do necropsies and collect information on noncoyote animals captured. We believe that future studies should collect information on all animals, not just animals targeted for capture, that are restrained.

It is difficult to use injury scores to compare differences in injury between these devices and others because injury scales have only recently been standardized using whole-body necropsies (International Organization for Standardization
1999), and scores are inappropriate for statistical comparison (Engeman et al. 1997). However, the newer capture devices and methods appear to reduce injuries relative to previous devices. Onderka et al. (1990) reported damage scores of 64.9, 21.6, 5.9, and 59.4 for unpadded jaw, padded jaw, Fremont snare, and Novak snare, respectively; Phillips et al. (1996) reported mean trauma scores of 103.3 for an unpadded trap and 29.0 and 79.3 for 2 padded traps; Hubert et al. (1997) found a standard coil spring to register a mean injury score of 97 and the same trap modified with offset jaws and lamination to be 80 . It is interesting to note that in this study the SoftCatch and the Collarum both surpassed the established injury acceptability threshold (United States of America-European Community 1997); for each device, greater than $80 \%$ of coyotes captured had no indicators of poor welfare. Further replication is required, but our results are promising and suggest that capture-system technologies and methods are improving in terms of minimizing injury to captured coyotes.

Because cable restraints in their current form do not wholly prevent injury, further research and development are still required, especially because the number of coyotes necropsied was low for the Collarum and WS-T devices. We examined other aspects of using capture devices, such as selectivity and efficiency, not just injury, and the data supported the conclusion of Way et al. (2002) that box-traps are not desirable for use on coyotes, especially for animal damage management. These data and our previous work (Shivik et al. 2000) suggested that the Collarum was appropriate for use in animal damage management; it had acceptable efficiency and injury scores. However, 1 coyote was killed when the snare loop failed to set properly. Future modifications to cable restraint systems could limit injuries to teeth; a coated cable, a displacement behavior "pacifier," or a Trap Tranquilizer Device (Sahr and Knowlton 2000) attached to the lock end of a cable may prevent tooth injuries (Shivik et al. 2000, Pruss et al. 2002).

\section{Management implications}

Inferences from our data should be limited to areas of the southwestern United States with relatively warm temperatures and sandy soil. Setting these devices in wet, freezing, or dense and resistant soils, for instance, may require adding more powerful springs or stiffer cables or using dry, 
sandy bedding to achieve similar capture efficiencies.

We examined capture devices relative to use in agricultural coyote damage management situations, and although the cage-trap performed poorly, there may be other situations, such as with urban or habituated coyotes, in which cage-traps may be useful. Similarly, the directionality of Collarum devices may preclude their use in some situations, or at the minimum cause trappers to rethink their method of "funneling" coyotes toward a capture device. The novelty of recent designs, including the WS-T device, will require additional training and effort to maximize efficiency and selectivity while minimizing injury.

It is interesting to note that our studies of capture devices showed improvement in efficiency, selectivity, and injury measurements when using newly developed devices. Private individuals and employees of United States Department of Agriculture's Wildlife Services are expending efforts to develop a wider variety of tools that will assist wildlife managers in the future. Although cagetraps and cable restraint systems may hold some promise for increasing selectivity and reducing injury, current evaluations suggest that capture devices should be chosen for the particular coyote capture management situation. That is, there is not a "best" capture device to recommend for use in all coyote-capture situations, and each system should be evaluated and applied based on its specifications and merits.

Acknowledgments. We appreciated the assistance of the Wildlife Services' Arizona and California state programs. The Havasu National Wildlife Refuge generously provided housing. K. S. Gruver's efforts in the field were greatly appreciated, and we thank the Wildlife Services program in Washington for lending him to us. All work was performed following approval by the National Wildlife Research Center's Institutional Animal Care and Use Committee, under study protocol QA962. Special thanks goes to C. Martens, ranch manager at the Killam Ranch.

\section{Literature cited}

ANDelt, W. F., R. L. Philuips, R. H. Schmidt, AND R. B. Gill. 1999. Trapping furbearers: an overview of the biological and social issues surrounding a public policy controversy. Wildlife Society Bulletin 27:53-64.

Cockrell, S. 1999. Crusader activists and the 1996 Colorado anti-trapping campaign. Wildlife Society Bulletin 27:65-74.
Engeman, R. M., H. W. Krupa, and J. Kern. 1997. On the use of injury scores for judging the acceptability of restraining traps. Journal of Wildlife Research 2:124-127.

GARRETT,T. 1998. The role of cage and box traps in modern trapping. Animal Welfare Institute, Washington, D.C., USA

GARRETT, T. 1999. Alternative traps. Revised edition. Animal Welfare Institute, Washington, D.C., USA.

Gruver, K. S., R. L. Phillips, AND E. S. Williams. 1996. Leg injuries to coyotes captured in standard and modified Soft Catch ${ }^{\circledR}$ traps. Proceedings of the Vertebrate Pest Conference 17:91-93.

Houben, J. M., M. Holland, S. W. JaCk, and C. R. Boyle. 1993. An evaluation of laminated offset jawed traps for reducing injuries to coyotes. Proceedings of the Great Plains Wildlife Damage Control Workshop 11:148-153.

Hubert, G. F., JR., L. L. Hungerford, And R. D. BluetT. 1997. Injuries to coyotes captured in modified foothold traps. Wildlife Society Bulletin 25:858-863.

Hygnstrom, S. E., R. M.Timm, and G. E. Larson. 1994. Prevention and control of wildlife damage. University of Nebraska Cooperative Extension, United States Department of Agriculture, Great Plains Agricultural Council, University of Nebraska, Lincoln, USA

INTERNATIONAL ORgANIZATION FOR STANDARDIZATION. 1999. Animal (mammal) traps, Part 5: methods for testing restraining traps. International Standard ISO/DIS 10990-5. International Organization for Standardization, Geneva, Switzerland.

LAACK, L. 1991. Ecology of the ocelot (Felis pardalis) in South Texas. Thesis, Texas A\&M University, Kingsville, USA.

LINHART, S. B., AND G. J. DASCH. 1992. Improved performance of padded jaw traps for capturing coyotes. Wildlife Society Bulletin 20:63-66.

Mowat, G., G. G. Slough, AND R. Rivard. 1994. A comparison of three live capturing devices for lynx: capture efficiency and injuries. Wildlife Society Bulletin 22:644-650.

ONDERKA, D. K., D. L. SKINNER,AND A. W.TODD. 1990. Injuries to coyotes and other species caused by four models of footholding devices. Wildlife Society Bulletin 18: 175-182.

Phillips, R. L. 1996. Evaluation of three types of snares for capturing coyotes. Wildlife Society Bulletin 24: 107-110.

Phillips, R. L., F. S. Blom, G. J. Dasch, and J.W. Guthrie. 1992. Field evaluation of three types of coyote traps. Proceedings of the Vertebrate Pest Conference 15:393-395.

Phillips, R. L., AND K. S. Gruver. 1996. Performance of the PawsI-Trip pan tension device on 3 types of traps. Wildlife Society Bulletin 24:119-122.

Phillips, R. L., K. S. Gruver, and E. S. Williams. 1996. Leg injuries to coyotes captured in three types of foothold traps. Wildlife Society Bulletin 24:260-263.

Phillips, R. L., AND C. L. Mullis. 1996. Expanded field testing of the No. 3 Victor Soft Catch Trap. Wildlife Society Bulletin 24: 128-131.

Pruss, S. D., N. L. Cool, R. J. Hudson, And A. R. Gaboury. 2002. Evaluation of a modified neck snare to live-capture coyotes. Wildlife Society Bulletin 30:508-516.

SAHR, D. P., AND F. F. KNOWLTON. 2000. Evaluation of tranquilizer trap devices (TTDs) for foothold traps used to capture gray wolves. Wildlife Society Bulletin 28:597-605.

Shivik, J.A., K. S. Gruver, T. J. DeLiberto. 2000. Preliminary evaluation of new cable restraints to capture coyotes. Wildlife Society Bulletin 28:606-613.

SKINNER, D. L, AND A. W. TODD. 1990. Evaluating efficiency of footholding devices for coyote capture. Wildlife Society Bulletin 18: 166-175. 
United States of America-European Community. 1997. Agreed minute and annex: standards for the humane trapping of specified terrestrial and semi-aquatic mammals. Brussels, Belgium.

WaY, J. G. 2000. Ecology of Cape Cod coyotes (Canis latrans var.). Thesis, University of Connecticut, Storrs, USA.

Way, J. G., I. M. Ortega, P. J. Auger, and E. G. Strauss. 2002. Boxtrapping coyotes in southeastern Massachusetts. Wildlife Society Bulletin 30:695-702.

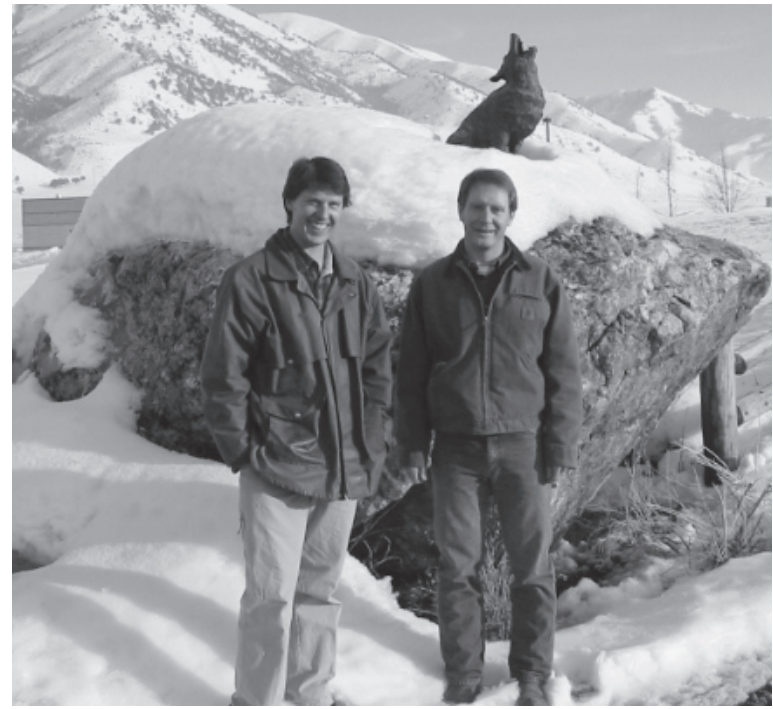

John A. Shivik (above, left) is the leader of the USDA, Wildlife Services (WS), National Wildlife Research Center (NWRC) Logan, Utah, Field Station. He received his B.S. from Frostburg State University (1990), M.S. from the University of California at Berkeley (1995), and Ph.D. from Colorado State University (1999). His current research goals involve incorporating studies of animal behavior and new technology into the development of new capture devices and effective nonlethal techniques for managing large predators. Daniel J. (Danny) Martin (right) is currently employed by the Colorado Division of Wildlife to

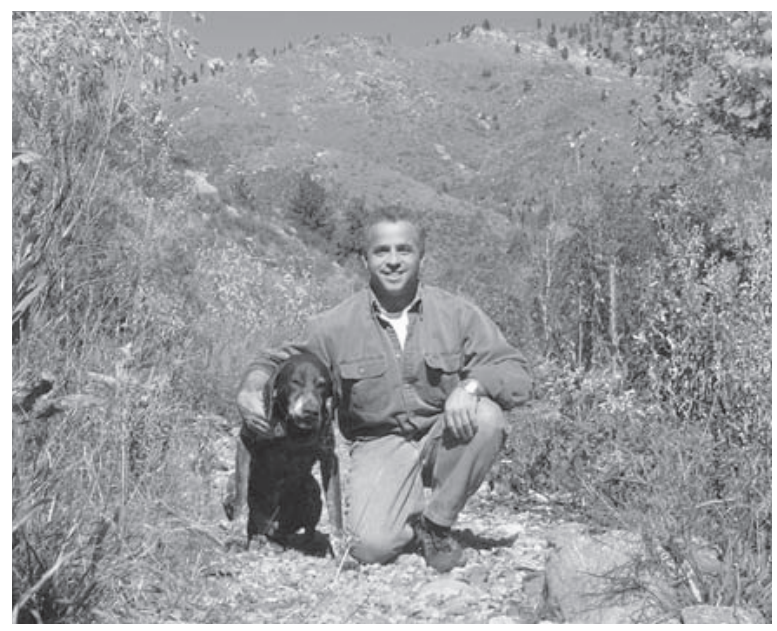

study swift fox populations in Colorado. He received his B.S. from Kansas State University (2000) and is currently completing his M.S. from Minnesota State University, Mankato. His research interests include animal movement, wildlife surveys, biodiversity, and wildlife damage management. Michael J. Pipas (left-hand photo, right) received his B.S. degree in biology from Indiana University of Pennsylvania (1988) and an M.S. in wildlife biology from Washington State University (1992). His career has been with WS, first as a research technician at the National Wildlife Research Center's Pullman, Washington Field Station (1992-1997), then at the Fort Collins headquarters (1997-2003), and since November of 2003 he has worked as a wildlife disease biologist for the WS operational program in Wyoming. John W. Turman is a district supervisor for the WS operational program in California; he has developed new snare and pan-tension testing devices for the program. Thomas J. (Tom) DeLiberto (above) has a B.S. (1985) from Colorado State University and an M.S. (1987) from Texas Tech University in wildlife biology. He received a Ph.D. (1993) in rangeland resources from Utah State University in livestock-wildlife relationships and a Veterinary Medical degree in 1997. Since 2003 Dr. DeLiberto has been the National Wildlife Disease Coordinator for WS, and his current duties include coordinating research and management of wildlife diseases and developing a wildlife disease surveillance and emergency response system. 